\title{
Tropes variations: the topic of particulars beyond Sellars's myth of the given
}

\section{Antonio M. Nunziante ${ }^{1}$ D}

Received: 4 September 2020 / Accepted: 15 July 2021 / Published online: 5 August 2021

(c) The Author(s) 2021

\begin{abstract}
The aim of this paper is twofold. First, I would like to bring into the light the almost unexplored Sellars's theory of particulars. Second, I would like to show its surprising degree of compatibility with the thesis supported by some contemporary tropists (Lowe, Gozzano and Orilia (eds), Tropes, Universals and the Philosophy of Mind, Ontos Verlag, 2008; Moltmann, Mind 113:1-41, 2004 and Moltmann, Noûs 47:346-370, 2013). It is difficult to establish whether Sellars possessed an own theory of tropes, developed independently by the classical form it took in Williams 1953, but as a matter of fact the peculiar features of his "complex particulars" model it is very much like Williams's theory. So much so that to all intents and purposes it represents a tropes variation. One of its strengths is that it is not part of a constituent ontology, since it is essentially developed from a linguistic and phenomenological point of view. It is for these reasons that this theory manages to avoid some of the classic objections to tropes and it shows to be compatible with the argument of Jonathan Lowe's "proper visibility" as well as with Friederike Moltmann's exquisitely linguistic interpretation of tropes.
\end{abstract}

Keywords Sellars $\cdot$ Tropes $\cdot$ Particulars $\cdot$ Epistemology $\cdot$ Naturalism $\cdot$ Early analytic philosophy

This article belongs to the topical collection "Demystifying the Given", edited by Andrea Altobrando and Haojun Zhang.

References to Sellars's works use the abbreviations that have become standard in the literature.

Antonio M. Nunziante

antonio.nunziante@unipd.it

1 Theoretical Philosophy, Department of Philosophy, Sociology, Education and Applied Psychology, University of Padova (Italy), P.zza Capitaniato, 3, 35139 Padova, Italy 


\section{Introduction}

I would like to do two things in this paper. First: to show the arguments through which Sellars constructs a theory of "particulars", which has been rarely discussed both by contemporary metaphysicists (Bailey, 2012; Campbell, 1990; Morganti, 2012), as well as by those who deal with Sellarsian studies (Olen, 2016; Rauzy, 2009). The main asset of this theory is that it highlights the confusion that bare particularists often make between "particulars" and "epistemic facts" by switching them with each other. This leads Sellars to defend the thesis that particulars (such as cabbages and kings) are not only fundamental individuals that, insofar as they are part of a single unified spatio-temporal system, represent the ontological counterpart of our ordinary talk (Strawson, 1959). Rather, they are "complexes" underlying an articulated logical structure that can be made explicit only in the light of a new interpretation of linguistic acts and behaviors (Sellars, 1952; Sellars, 1954).

Secondly, I would like to show how this model represents a powerful variation of the tropes theory. My aim in this case is to show how Sellars's version, developed independently from Williams's classic version (Williams, 1953a, 1953b), combines very effectively with some theories put forward by contemporary tropists. In fact, I would like to show how his arguments reinforce some of their specific positions (Lowe, 2008; Moltmann, 2004, 2013) and indeed integrate them in a reciprocal way.

Given the scarce popularity of this theory, my exposition will be slightly asymmetric: I will analyze in an extended way the "complex particulars" theory as an alternative position (not immediately tropist) to bare particularism and to bundle theories; while I will reserve the last part of my analysis for the topic of tropes (which is much better known and with respect to which a consistent literature already exists). In this last section I will try to show the surprising degree of integration between the position defended by Sellars and some of the proposals made by some contemporary tropists. ${ }^{1}$

\footnotetext{
${ }^{1}$ In the analyses that follow, there will be several points of convergence with the thesis advanced by Morganti (2012). However, there will also be differences involving methodological and interpretive issues. Methodological, because while Morganti focusses on the topic of the ontological constitution of material objects, trying to show how Sellars's theory of particulars represents a "third way" between resemblance nominalism and trope nominalism, I focus instead on the epistemological and linguistic aspects of his theory. And it is precisely in moving from these premises that I develop the hypothesis of a successful integration of Sellars's theory with some contemporary variations of trope theory. I do not believe, in fact (unlike Morganti), that Sellars's theory can be combined with the classical formulation of the tropes proposed by Williams and defended by Campbell. This leads me to clarify the main differences with the overall thesis advanced by Morganti: I doubt, in fact, that the arguments developed by Sellars in LCP, P and SRLG represent the immediate formulation of an ontology of particulars. Sellars's final aim is not to lay the foundations of a "constituent ontology", but rather to develop a reflection on the epistemic conditions involved in our discourses about particulars (it is a "study of the foundation of logic"-Sellars, 1949, pp. 313-314). An ontological frame can perhaps be deduced indirectly, but this is not his primary goal and indeed in these writings he cautions the reader against drawing these kinds of ontological reading (Sellars, 1952, p. 92). Sellars's basic particulars should not be considered in Williams's fashion as sort of mini ontological bricks constituting "the alphabet of being", but rather as logical prerequisites that make our talk about particulars intelligible: on this point, his proposal remains radically divergent from that of Williams, and Morganti himself recognizes that the question is highly controversial and probably destined to remain open.

However, it is true that (a) it is possible to interpret Sellars's project by going beyond his littera, and thus developing from its premises a possible particularist ontology (in which the features of "resemblance" and "trope" nominalism merge with each other); and that (b) the theory of particulars can
} 


\section{The unexplained role of particulars in Empiricism and the Philosophy of Mind}

In one of the most significant passages of the first section of Empiricism and the Philosophy of Mind, Sellars introduces the reader to an epistemological antinomy that, in a sense, sets up the agenda of the following discussion. It is phrased like this:

(a) It is particulars which are sensed. Sensing is not knowing. The existence of sense data does not logically imply the existence of knowledge, or

(b) Sensing is a form of knowing. It is facts rather than particulars which are sensed. (Sellars, 1963, p.129)

There are several keywords that recur in these brief passages ("sensing", "knowing", "facts", "sense-data"), one of which shines with a sort of indirect light because here, as elsewhere in EPM, it is never explained: it is the term "particular", to which sense-datum theorists refer. ${ }^{2}$

What in this passage Sellars omits to say is that in the analytic tradition there had been and there was, still very much alive at the time of EPM, a huge metaphysical dispute about the nature of particulars. It was a controversy that Sellars knew closely, probably from the time of his studies at Oxford in his youth, but which he had certainly paid attention to over the last ten years, since it had been taken up first by Gustav Bergmann $(1947)^{3}$; then it had interested him in his capacity as Editor of "Philosophical Studies" position of his two essays On the Logic of Complex Particulars (Sellars, 1949) and Particulars (Sellars, 1952).

Reconstructing the history of this debate has its own intrinsic relevance, both because it helps to better understand some early features of the history of analytic philosophy, but also because it plays a significant role in the development of

\footnotetext{
Footnote 1 (continued)

certainly be understood as the prelude to a reform of the ontology of the manifest image of the world. Along this line of interpretation, it is quite legitimate to assume that the accomplishment of this task may coincide with Sellars's late project of a metaphysics of absolute processes (that represents the ontology proper to the scientific image). But these are aspects that are not part of my analysis, which instead remains focused on the epistemological perspective (which includes aspects of phenomenology and philosophy of perception) and on the logical-linguistic view. Notwithstanding, the perspectives put forward by the two papers have some common theoretical features and are in some ways complementary.

2 According to deVries-Triplett, Sellars assumes without any further argument that what is known is facts rather than particulars. Moreover, they say, he "does not make explicit here his reason for rejecting knowledge of particulars". (see deVries-Triplett, 2000, p. 11). For a first introduction of the facts vs. particulars antinomy, see also the glossary provided by them at the end of the text (deVries-Triplett 185).

3 It is worth remembering that Sellars and Bergmann were colleagues at the State University of Iowa between 1940 and 1946 .

4 The first volume of "Philosophical Studies" (no. 5), which Sellars edited together with Feigl, hosted a contribution by J.R. Jones entitled Simple Particulars.
} 
Sellars's own thinking. ${ }^{5}$ It is for this reason that in the following paragraphs I will try to explain the complex logical pattern that structures the issue of particulars in the texts immediately preceding EPM: the main references of the analysis will therefore be the two essays, $\mathrm{P}$ and LCP, which in a sense serve as a premise to the antinomy presented in EPM.

\section{Nothing in particular: bundle theory vs. bare particulars}

What makes a blue a "particular instance of blue"? What does it mean, namely, that a universal quality is not only repeatable with multiple instantiations, but also currently occurring in such a way as to make that blue a particular instance of blue? This is probably one of the most classic and controversial issues of the entire Western philosophy. And starting from Aristotle and from the innumerable historical interpretations of substance-attribute theory, it has also become a classic in the repertoire of analytic philosophy. ${ }^{6}$

The metaphysical framework of the problem obviously makes all the difference in the world. In a classic "Aristotelian" two-category ontology there are not so many alternatives, because in a language endowed with a subject-predicate syntax the dualist solution emerges almost inevitably: individual substances play the role of concrete particulars, whereas abstract universals, or qualities, are placed in a predicative position (Campbell, 1990, pp. 5-6). It goes without saying that such a picture is made more complicated by the fact that in every daily situation we are confronted with there are two moments that are intertwined within the particularity of each single substance, namely the fact that natural objects are never indeterminate (i.e., every object is a definite object rather than any other) and the nature of such particularity (i.e., objects are always marked by a complex of properties whose role is to determine the kinds to which the particular belongs-Campbell, 1990, p. 6). The question thus becomes: "how much of the whole object is the substance?" (Campbell, 1990, p. 7). That is, how do such heterogeneous features (qualities and particularity) come to interpenetrate each other in the specific case of a single object instantiation? Hence the classical controversies that, as a matter of fact, have still not been exhausted to this day.

One of the most traditional and successful solutions to this philosophical puzzle was that provided by the so-called theory of bare particulars. Passing over the fact that there were-and still exist today-many different versions of this theory (Sider, 2006; Garcia, 2014; Connolly, 2015), a plausible standard version of it tells us that qualities always express a general property and that what makes blue a particular blue consists in the fact that the quality is joined with a substantial element devoid of qualitative determinations (Maclean, 2014, pp. 11-12; Loux, 2015, p. 18). The

\footnotetext{
5 In 1955, for instance, Sellars acts as a discussant with Peter Strawson in a symposium on Logical Subjects and Physical Objects and again in 1958 he would return to the subject in the first draft of his essay Meditations Leibnitziennes.

6 See MacBride (2018).
} 
latter, however, brings to this type of union the fact of being something particular. When we happen to say "this-blue", we are therefore referring to something general (which allows us to recognize this blue as a blue), but also to something particular (underlined by the use of the indexical) which is not grasped by any descriptive or conceptual resource.

If we accept a theory of this kind, the solution to the puzzle is easily at hand. The only drawback is that bare particularism is likely to open up problems as serious as those it intended to solve. Several criticisms have in fact been raised against this theory (Maclean, 2014, pp. 13-15) and in the early analytic debate there were different stances in this regard. There were authoritative positions against it (Stout, Russell), but also favorable positions (McTaggart, Bergmann, Alston), and subtly intermediate opinions (Williams). In his two works of 1949 and 1952, Sellars strives to show that the root of the error of bare-particularism consists in a confusion between "facts" and "particulars", and it is through this route that he construes part of the conceptual scaffolding that supports the first sections of EPM.

Before analyzing his position, however, it is worth referring also to what at the time was considered its great rival theory. This was the path followed by Russell, who tried to give rise to a particular-free theory, namely a theory that justified particulars, but without resorting to substratum theories and not even to the so-called egocentric particulars (Russell, 1940).

\section{Bundle strategies}

Russell's own view is that universals themselves can play the game of particularization, combining with each other according to determined qualitative ties (they form a "series"-Maclean, 2014, p. 59). The basic idea was to give up the bare factor. Russell suggests that the cases of particular blue are particular instantiations of blueness and that the particular factor is but a function of the way in which a plurality of qualitative determinations are linked together. In this case the link between the universals is treated as if it were itself a particular (Garcia, 2015, p. 137). ${ }^{7}$ He therefore seemed to think of his bundles of "compresent qualities" as complexes of universals.

From such a theoretical approach he believed he could derive a couple of considerable consequences:

(1) in the description of the empirical experience, one can dispense with the use of egocentric particulars (Russell, 1940, p. 128);

(2) one can instead use a noun to describe the content of a particular experience (Maclean, 2014, p. 45). We can in fact substitute "this is hot" with "hotness is part of W"; meaning by that: "hotness is one of the qualities composing W" (Russell, 1940, p. 128).

\footnotetext{
7 The particularity and its uniqueness lies in the "assemblage" of qualities, see Jones (1950), p. 70. It is "the complexity of their qualities that particularizes them", see Maclean (2014), p. 61.
} 
Russell's final target is an extremely pleasing result to science, for if the theory stands, the complex wholes become, in effect, themselves particulars and moreover completely de-subjectivized. They can be expressed according to a third-person point of view: they can be made objects of authentic empirical knowledge, without having to resort to the metaphysical dualism implied by substratum theories. To explain the particularity of a given object, one is no longer forced to invoke the presence of a bare-factor devoid of qualities ("an unknowable something in which predicates inhere"-Russell, 1940, p. 97), which remains unknowable precisely in those aspects that characterize its empirical nature. Rather, the particularity emerges from the way in which complexes of certain qualities interplay with each other. According to Russell, in fact, when we transform a sentence of the form "this is hot" into "hotness is part of W", what happens is that we are confronted with a grammatical transformation that produces a profound epistemic transformation. The predicate, in fact, is now transformed into a noun which, however, is not to be understood as referring to a substance, but rather to "a bundle of coexisting qualities" (Russell, 1940, p. 97). The overall idea is that particulars can be obtained from universals and in doing so we get rid of an "unknowable" (Russell, 1940, p. 98), in the sense that we get rid of that bare particulizer, whose presence was implied by the constraint of the classical two-category ontology. This new particular-free language would be the language of sense-data, which can be acquired through acquaintance, namely through direct knowledge (Rauzy, 2009, p. 88).

\section{The mission of complex particulars}

Sellars proposes a sort of third way. Particulars are not bare particulars and they are not even bundles of qualities, but rather complex particulars: they are complexes of "basic particulars" (Sellars, 1952, p. 187). They summarize classes of situations or qualitative episodes (he calls them also "qualia"). ${ }^{8}$ The fundamental characteristic of this third way, however, is that it does not represent a "third way" at all, given that what Sellars is trying to do is to attack the very frame that supports the aforementioned strategies.

\footnotetext{
${ }^{8}$ Here and in the rest of the paper I use "episode" or "situation" indifferently. As we will see below, Sellars does not use this specific terminology either in LCP or in P, but he limits himself, especially in $\mathrm{P}$, to distinguishing qualia from qualities. However, I find that this terminology is didactically effective in order to clarify the delicate distinction made by Sellars between qualia and qualities and, besides, it has its own hermeneutical justification. The use of the term "episode", according to the meaning that I attribute to it, is attested in fact in ML where Sellars uses it, having in mind, via Broad, a certain way of understanding the nature of Leibniz's complete concept ("the individuality of a substance can be understood only in terms of episodes in its history", Sellars, 1959, p. 154). As we shall see later, the reference to Leibniz is absolutely central to the arguments developed by Sellars regarding particulars (as noted also by Rauzy, 2009, pp. 91-96): see note 8 below. The use of the term "situation" is attested in Broad ("the distinctions between the nature of a thing and its various situations") in the pages to which Sellars refers both in LCP and in ML (see Broad, 1933, p. 264) and it serves simply to stress the fact that an episode, or indeed a situation, is not a fact (as reiterated in Sellars, 1959, p. 163). There are facts that express propositional content and there are situations that cannot be traced back to facts. But for more on this see below.
} 
The starting move consists in disambiguating the very notion of "predication", which is only possible by focusing on the concept of "propositional function". In LCP Sellars observes that utterances such as (A) "Fido is a dog" and (B) "Fido is angry" do not possess the same logical form, despite their similar surface grammar. Indeed, in the case of (A) the predicative relation can be understood extensionally, since Fido belongs "as a whole" to the class of dogs; but this extensional move is not entirely valid in the case of (B). Fido, in fact, is not by himself (as a whole dog) exemplifying anger, but rather there is something within him, namely a particular emotional state that is a specimen of anger (Sellars, 1949, p. 311). Such emotional state is then construed as an "ingredient" of Fido. In other words, Sellars deploys a Leibnitian logical tool to disambiguate that particular type of predication, which formalized becomes:

(Ey) I $(y, x) \& f(y)$. There is a $y$ such that $y$ is an ingredient of $x$, and $y$ is a specimen of $f$ (Sellars, 1949, p. 314).

This sophisticated logical apparatus is displayed to make us aware of the almost inevitably thingifying attitude that is embedded in our ordinary talk: we normally treat both particulars as "things" that instantiate certain properties $(f \mathrm{x})$, and properties as well as instances of qualities that themselves "belong to things" (in Sellars's fashion, we treat $f(\mathrm{x})$ as $f$-thing(x) - Sellars, 1949, p. 313). It is this thingifying attitude that Sellars wants to put under pressure, since to speak of things endowed with properties, or of "thingish" properties, is to fall prey to the metaphysics of the substratum and to the aporias concerning the individuation of qualities (Sellars, 1949, p. 313$){ }^{9}$

His proposal is therefore framed like this: instead of speaking of things endowed with properties, we should rather speak of "complex particulars", whereby we should intend a non-relational way of rethinking predication. Thinking of Fido (the subject of our utterance) as a complex particular helps us to understand that we are not dealing with a particular substance that somehow instantiates multiple qualities, but rather with a complex in which multiple simple ingredients are functionally linked.

In these passages of LCP (which would later return in essays such as Sellars, 1959) the reference to the Leibnitian model of ingredients is quite explicit and it is somehow curious that only few scholars have noticed it (Nunziante, 2018; Rauzy, 2009). Needless to say, we cannot delve here into the complex relationship that Sellars entertained with Leibniz, but we can at least limit ourselves to doing two things: (1) keeping in mind that in Leibniz we find a powerful non-relational model of predication that represents a logical variation on the Aristotelian legacy of late scholasticism; (2) quoting a good definition of ingredient. To this regard, there is a good passage:

\footnotetext{
9 "The truth of the matter is that the word 'thing' as we are using it-and our usage is close to the grassroots - stands for a type (or family of types) of logical structure to which the concept of substance properly explicated belongs, but which the latter concept by no means exhausts". LCP, 313. The point was also emphasized by Peter Simons, when observing that our "natural tongues constrain us to talk about things by putting noun phrases in subject position and predicating”. (See Simons, 1994), p. 565.
} 
When we speak of inesse with respect to some place, or of being an ingredient of something, we mean the fact that when something is posited the ingredient is also posited, and this happens without the need for any inference. Thus, when a finite line is posited, so are its extremes, its parts. What is in something and is homogeneous to it is called a part, and the thing to which it pertains is called the whole, that is, the part is a homogeneous ingredient. (Leibniz, GM VII, p. 19)

Note the clear proto-transcendental claim employed here by Leibniz: when something is posited, the ingredient is also posited (without assuming this to be a matter of causal necessity). If Fido is posited, his ingredients are also posited. Note the conclusion as well: the part is an ingredient of a whole homogeneous to it, as a line is part of a straight line in so far as they both share extension, or the hand is part of the arm in so far as they both belong to the same portion of a physical extended body. But there are also ingredients that are not homogeneous to the whole, as points are not part of the line, or monads are not material elements of the organic body (Leibniz, A VI 4 B, p. 1669). The notion of ingredient thus is more primitive than that of "part", at least from a logical point of view, for while we can think of simple substances that are not the additional sum of material elements, we cannot imagine anything that is completely devoid of logical requisites. In the Leibnitian world, in fact, when something exists, there are also reasons that justify its being as well as its intelligibility ("nihil est sine ratione" - Leibniz, GP, p. 602). The part/whole relation therefore is not so much a compositional quantitative relation, but rather an ordered relation, insofar as a functional relation holds among ingredients (the whole is a function of complex co-ingredience relations-Rauzy, 2009, p. 98).

Sellars's adherence to this theoretical model is precise to the smallest detail, because if we understand the logical subject Fido as a "complex particular" and the abstract predicate of anger as an ingredient of him, it is evident that any dualism between particulars and universals immediately fades away. It is no longer, in fact, a question of understanding how a relationship between non-homogeneous terms stands, since Fido's being angry simply becomes a requisite of his individual history: a logical moment implied by his very nature. Anger is but a moment in Fido's individual history. Fido in its entirety is a complex particular: the functional sum of an infinite collection of peculiar features. This highly sophisticated logical model will be developed and transformed by Sellars along a purely linguistic direction (Sellars, 1952) until the formation of a non-relational functional role semantics (Sellars, 1953, 1954) that represents one of the focusses of his whole philosophy. It is precisely this linguistic variation that, as we shall see, will allow him not only to avoid the problems associated with "bundle" theories and bare particularisms, but also to distance himself from classical trope theories.

The notion of a complex particular therefore serves as a logical and metaphysical pivot to replace the entire framework that had hitherto supported the debate concerning the particularization of universals. The attempt is thus extremely ambitious, since in it are linked logical, ontological and grammatical issues, as well as historical-philosophical ones, in the sense that, according to Sellars, the question of particulars is the result of a long-term philosophical tradition. 
There are several reasons that justify the peculiar nature of this project: some of them, as we have seen, are purely logical (Sellars espouses a particular type of nominalism), others of a linguistic nature, and finally a more general reason, particularly evident in EPM, that has to do with the adoption of a naturalistic attitude. It is quite clear, in fact, that within a naturalistic perspective, the questions of universals, of abstract and bare entities, must all be epistemically reframed. But this is possible only by cleaning up the underlying ontology.

\section{The false step root: particulars, not facts!}

Bare particularists and bundle theorists confuse a fundamental point: they both mix up particulars with facts concerning particulars. And they both deal with facts concerning particulars as if they were themselves particular. Here is a first quotation:

To say that a blue particular consists of Blue and a particular is indeed to talk nonsense, but it is nonsense which arises not out of a dualism of particulars and universals, but out of a confusion between particulars and facts (Sellars, 1952, p. 188). ${ }^{10}$

For Sellars, a fact always has a certain kind of structure. Facts are "items of the form something's being thus-and-so or something's standing in a certain relation to something else" (Sellars, 1963, p. 128). The notion of a fact, it has been said, "is the 'material mode' equivalent of a proposition" (deVries-Triplett, 2000, p. 185). Thus, facts have particulars as constituents, as Romelu and Milan are constituents of the fact that Romelu is working as a football player in Milan. According to Sellars, however, the point is not that we cannot know particulars, but that to know a particular is to know a set of facts about it" (deVries-Triplett, 2000, p. 185). Targeting bare particularism, Sellars argues:

Any dualism of universals and particulars amounts to a distinction within things between a factor responsible for the particularity of the thing, and a factor responsible for its character; in brief, a this-factor and a such-factor. But surely this is exactly the doctrine of bare particulars! (Sellars, 1952, p. 188)

The mistake lies in a sort of logical confusion. When we talk about facts, we must always keep in mind that we are talking about propositions of the form " $a$ is $\Phi$ " and in this case, but only in this case, it makes sense to say that there is "a thing" that has $\Phi$ as a "component" and that this thing is itself an instance of $\Phi$.

The word "thing" is the weak point of the whole affair. It is typical of propositions that they combine as components of the proposition something that acts as a subject and something that acts as a predicate. But all this can lead to a "philosophical monstrosity":

$\overline{10}$ This passage is also quoted in Rauzy (2009), p. 90. 
Thus, the notion of a thing which (1) has $\Phi$ for a component, and yet (2) is an instance of $\Phi$, is a confusion which blends $a$ and the fact that $a$ is $\Phi$ into a philosophical monstrosity. (Sellars, 1952, p. 188)

Once again, as was already denounced in LCP, the confusion gravitates around the role that notions such as "component", "part", "instantiation", play in the interpretation of a subject-predicate statement. And once again a specific example will help us to understand how this kind of interpretative monstrosity is generated (whose ontological counterpart is none other than the metaphysics of substance denounced by Sellars). Let us resume the case of the utterance "Fido is angry" and let us make it explicit in the terms of the observation made by Sellars in the previous quotation, i.e., in the terms of.

"the notion of a thing [Fido] which (1) has $\Phi$ [anger] for a component and yet

(2) is an instance of $\Phi "$.

The logical non sequitur of keeping together (1) and (2) becomes evident, for if we consider Fido as a whole entity, and the anger as a component of it, we cannot possibly conclude that the whole is an instance of its part (Sellars, 1949, p. 310). Such a logical conundrum is firmly emphasized by Sellars in P:

Suppose that a certain particular $a$ exemplifies $\Phi$. Then $a$ is an instance of $\Phi$, but $\Phi$ is not a component of $a$. On the other hand, $\Phi$ is a component of the fact that $a$ is $\Phi$. But the fact that $a$ is $\Phi$ is not itself an instance of $\Phi$. (Sellars, 1952, p. 188)

When we say that "Fido is angry", it is as though we were presupposing more than we are actually saying, which is why we are necessarily called to clarify the logical levels of our utterance. On the one hand, we are in fact reporting that there is a certain particular individual who exemplifies a general state of affairs (Fido's anger, which we identify as a particular case of a universal concept or quality). On the other hand, we are implying that it is not Fido as such that exemplifies such universal quality, because if anything, it is his particular emotional state that instantiates the general characteristic of anger. And so again: on the one hand, anger is a component of Fido's being angry, but on the other hand, this anger cannot be understood as a part of that particular individual that he actually is. It is as though particularity and universality could never be held logically together, no matter how much they are related by our statement, and no matter how much in the facts of the world they somehow combine with each other.

The way out of this dilemma, according to Sellars, consists in disambiguating both the concept of universal quality and that of particularity, because only in this way can their logical opposition be deconstructed. A first mistake consists, in fact, in treating quality as if it were a thing added to another thing (as a physical component of something else), whereas Sellars invites us instead to explore the idea (taken up by G.F. Stout) that qualities are "as particular as the thing itself" (Sellars, 1949, p. 311). ${ }^{11}$ A second complementary error consists in treating the particular as if it

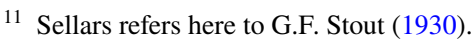


were a simple bearer of qualities (according to the model of bare particularism) and not as a "complex particular", that is, as a complex of qualitative (particular) episodes. If we adopt this double shrewdness, the sense of the statement also changes from a logical point of view, because in this case we no longer deal with a particular Fido, on one side, and a universal anger, on the other, but with two qualitative episodes that are both particular.

In other words, a relationship of reciprocity takes place only when Fido's individual existence is understood as a complex of qualitative modes (among which we include his emotional states). In this case, but only in this case, we are confronted with the situation previously described (" $a$ is an instance of $\Phi$, but $\Phi$ is not a component of $a$ "-Sellars, 1952, p.188), for here we are no longer dealing with a relationship of "instantiation", but rather of "identification" in its strongest sense: $a$ is now the qualitative episode $\Phi$ (it fully coincides with it). The predicate has been absorbed into the subject (praedicatum inest subjecto), since the universal quality has become effectively particularized.

Such work of deconstruction, however, cannot be at all clear until the positive characterization of Sellarsian particulars has been fully developed. Provisionally, we must bear in mind that while our dictionary has sufficient resources to name complex particulars such as Fido, cabbages or kings, the simple elements of such complexes (which Sellars calls "basic particulars") are not directly transcribable into linguistic forms, and in this sense they are not even "known" in their immediacyfor they are rather "sensed". But how should we characterize them epistemically? The answer will unfold gradually. The main idea is that they should be understood as logical requisites implied by our ordinary talk, and that the relationship between complex and basic particulars implies a particular type of logical resemblance. The latter in its turn will exclude the hypothesis of an ontological constituency (unlike Williams's theory of tropes), for it rather points towards a linguistic and transcendental direction.

Before analyzing this issue, however, we need to be aware that the fundamental mental change that is required to enter the world of complex and basic particulars consists in realizing that here we are not talking about things or facts, but about situations, or episodes. There is a noble ancestor of this turning point, namely Leibniz. As we know, for Leibniz, individuals are not "thing-like" substances, but they are ordered systems of qualitative episodes (there is a rule of order that binds together every single qualitative episode of their life). Substantiality is not so much saturated by the faculties or dispositions pertaining to the individual, but from the normative link subsisting between episodes. ${ }^{12}$ There is not something like a Socratesthing which happens to be rational, but there is a collection of particular episodes

\footnotetext{
12 "The notion of the nature of an individual substance is a venerable one though not without its puzzles. But this notion has obviously taken a new twist in Leibnitz's hands. Leibnitz was not the first to conceive of the nature of an individual substance as accounting for its individuality. He was, however, the first to see clearly that the individuality of a substance can only be understood in terms of episodes in its history, and not merely the capacities, powers, dispositions - all, in principle, repeatable-which were traditionally connected with the natures of things". ML, 154. (See Nunziante, 2018, p. 38; Di Bella, 2005, pp. 200-220).
} 
nomologically connected that saturates his individuality. Sellars was indebted to Charlie Dunbar Broad for this reading of Leibniz and it should be noted that this reference constantly reappears in the plexus of writings in which he deals with particulars (since it represents, as we can see, a powerful historical variation of the classic concept of "nature"). ${ }^{13}$

Let us also try to give a non-Sellarsian example, with the sole purpose of facilitating the change of perspective required in the transition from facts to particulars. Some help in this sense comes from a tale by Borges, contained in Fictions: Tlön, Uqbar, Orbis Tertius. In Tlön's universe, Borges claims, the world "is not a concourse of objects in space; it is a heterogeneous series of independent acts" (Borges, 1964, p. 24). In the conjectural Ursprache of Tlön there are two different kinds of languages. In the idiom of the northern hemisphere "the prime unit is not the verb, but the monosyllabic adjective. The noun is formed by an accumulation of adjectives" (Borges, 1964, p. 25).

They do not say 'moon', but rather 'round airy-light on dark' or 'pale-orangeof-the-sky' or any other such combination. In the example selected the mass of adjectives refers to a real object, but this is purely fortuitous (Borges, 1964, 25).

In the literature practiced on Tlön there are no words that correspond to objects, but there are aggregated structures of terms that correspond to a single ideal object: "the color of the rising sun and the faraway cry of a bird"; "the sun and the water on a swimmer's chest"; "the vague tremulous rose color we see with our eyes closed" (Borges, 1964, p. 25). Borges says:

There are famous poems made up of one enormous word. This word forms a poetic object created by the author (ibid.).

The similarities with Sellars's own position are indeed striking. First of all, we are excluding the resources of traditional ontology (in Tlön there are no spatial objects as we can understand them) as well as those of ordinary language. Words do not denote things, but capture particular situations ("the sun and the water on a swimmer's chest"): the language is wholly situational, so much so that entire poems are composed of "one enormous word" that corresponds to the poetic situation intentioned by the author. The poetic object of Tlön should be thought of as a complex particular, that is, as a whole that is not composed of parts, but is rather the result of a functional relation with multiple ingredients in the proper Leibnitian sense previously encountered. Namely, the complex poem, despite its being sequentially spelled by vocalizing many words, counts as a particular individual (unum per se) in the sense that each of its basic features cannot be considered independently of the whole poetic system. It is a situation in which the dualism between "abstract" and "concrete" is no longer epistemically reliable, because instead of thinking of a universal genus subsuming a multitude of individuals, we have instead to think of a

\footnotetext{
${ }^{13}$ Let us remember the epoch-making distinction that Sellars places at the dawn of modernity between a thing-nature framework and an event-law lexicon: between the lexicon of substantial natures interpreted as "things" and the lexicon of events subsumed under the law of physics. See APM, 546.
} 
quality that has been entirely particularized: in this case we are more dealing with an individual that is a genus unto itself.

Sellars's strategy, like that of Borges (and like Leibniz before) is strictly nominalist. Basic particulars are not defined by instantiation of properties, but on the contrary: they are infimae species (they are genus to themselves). Complex particulars, on their side, are not general predicates in the traditional sense, but they are rather complexes of particular episodes. Sellars talks of greem to refer to cases of particular green, just to avoid the word "green" and just to make us certain that in this case the word green would be useless: a greem is a basic particular, a situational episode; whereas "green" is a word of our ordinary language; it is a complex particular, namely it can be treated as an epistemic fact that implies a cluster of basic situations. Admittedly, one could argue that in speaking of a "greem" we are already treating it as a common noun (i.e., as a universal) and this objection is certainly reasonable. Sellars's linguistic expedient, however (i.e., the use of a word that does not exist in ordinary language), is an auxiliary tool that serves to disambiguate once more the notion of predication, namely it serves to keep distinct the epistemic dimension of the discourse (in which we talk about particulars, enunciating a set of facts around them) and the logical dimension of it (in which we reason about the logical requirements implied by our talks about particulars). Greems are not predicates nor terms, but rather logical conditions that are required to make sense of our talk about particular greens. If we treated them as verbal units that enter into the composition of an epistemic fact, we would miss such distinction and we would instead go back to that confusion between facts and particulars that was the root of the logical nonsense denounced by Sellars with regard to bare particularism (Sellars, 1952, p. 188).

\section{Greem, grom, grum}

The predicate "green", thus, can be preserved as a resource of ordinary language, but at the same time we have to understand that we are dealing here with a "complex logical structure" (Sellars, 1952, p. 192). Talking about "greens" (epistemic level of the speech) implies a complex of particular episodes, in the sense that green-qualities imply a complex of green-situations (greem). We are inside a new conceptual framework, whose fundamental rule is the following:

what is ostensibly a single particular exemplifying a number of universals, is actually a number of particulars exemplifying simple universals. (Sellars, 1952, p. 188)

There is the stipulation: we are asked to imagine a universe of basic particulars, each of which is the instance of one and only one simple universal (Sellars, 1952, p. 187). What apparently presents itself as a particular (as for instance a green leaf) is actually a cluster of basic particulars, each one exemplifying a single qualitative episode. ${ }^{14} \mathrm{~A}$ simple, factual predicate ("green") is actually a "complex": a function of a higher order that expresses a relationship among more basic elements (qualia).

\footnotetext{
14 The "complex particulars", Sellars says, are "logical constructions out of particulars proper" (Sellars, 1952, p. 189).
} 
The point is pivotal: the basic particular greem is not a green fact and, by stipulation, it cannot even instantiate a quality that is different from itself: greem stands for a quale, it does not instantiate the general quality-Greemness:

Neither Greemness, nor the fact that $a$ is greem is greem. It is $a$ that is greem. [...] Greemness is not an element of $a$, though it is of the fact that $a$ is greem. (Sellars, 1952, p. 189)

Greems are characterized, so to speak, by the fact that they are universal in themselves: they are qualitative episodes (let us think of the world of Tlön previously mentioned). They are entirely qualitative situations: "the 'this-factor' ... is nothing more nor less than an instance of $\Phi$ ” (Sellars, 1952, p. 188).

Complicated as it is, this complex apparatus in Sellars's view accounts for the subject-predicate form that we use in our everyday language:

The subject-predicate form of ordinary language can only be understood in this setting. The objects designated by the subject term in singular sentences of this form are, without exceptions, complex particulars. (Sellars, 1952, p. 191)

To recap once again:

It is a mistake to speak of basic particulars as instances of qualities, and it was for this reason that we introduced the term "quale" to designate the simple non-relational universals of which basic particulars are instances. It is even more obviously a mistake to speak of basic particulars themselves as qualities, and proclaim that the qualities of things are as particular as the things themselves. (Sellars, 1952, p. 191)

Basic particulars are not sic et simpliciter instances of qualities (otherwise we would reintroduce the topic of bare particulars from which we want to move away), but they are qualia. This does not mean, on the other hand, that they should be regarded as traditional universals. This would be a mistake, for if we considered qualia as qualities we would get dangerously close to Russell's bundle-theory, which we instead want to avoid. Swapping qualia for qualities, Sellars says, is a "type confusion" that mixes two different levels of structure (Sellars, 1952, p. 191).

The newly defined ontological picture allows us to reframe the entire issue: "green" represents a complex particular, a compendium of "green situations" (each one is rather greem than green). The complex particular "green" does not immediately refer to a green-thing and it does not even mention an abstract entity ("Greenness"). It rather summarizes a bond between classes of green situations. It does not denote things, but establishes a functional tie between situations that are connected by family resemblances.

How do, in fact, greems constitute themselves in class? What is the relationship between the greem-class and the quality-greemness?

This specific issue is first approached by accomplishing a sort of lateral move:

To sketch the background of this new picture, we need a broader canvas. Its fundamental theme can be put by saying first that the meaning of a term lies 
in the rules of its usage, and then adding that the rules in question are rules of inferences. (Sellars, 1952, p. 194)

The "broader canvas" to which Sellars refers serves to include in his "new picture" a fresh theory of language, namely to incorporate as an essential counterpart of his analysis that particular theory of meaning he was giving shape to at that time. The remark is truly meaningful, because the newly defined frame of particulars is liable to a fine-grained linguistic transposition provided, however, that the functioning of language is understood in a new way.

The idea, more or less, is that the meaning of a word consists in following a rulegoverned pattern of behavior. The word "green" does not so much denote the quality of being green, nor does it refer to green-objects, but rather it encompasses a rule of use, since it summarizes the ways in which we happen to know how to spend it correctly in the different pragmatic contexts of its employment (Sellars, 1954, p. 327).

Such idea of family-association seems therefore the right track, allowing us to understand the link subsisting between different greems:

The way is therefore open to an identification of qualia [...] with the classes of their instances in all words of the family with which each is associated. Thus, Greemness would be identical with the class of all grums in the family of worlds with which is associated the battery of simple universals one of which is Greemness. The identity of qualia with these classes of their instances provides a basis for the analysis of the relations of universals and classes at the level of complex particulars. (Sellars, 1952, p. 198)

We are in an open-texture extensional context, in which greems are no longer defined by intension. The relationship with the universal is therefore reversed: the quality is no longer an abstract universal, but a function that classifies not so much contents, but rather usage bonds.

To be even clearer, greem is not a given chromatic content (a particular that in itself would count as an epistemic content), but a basic episode whose epistemic value is - and cannot but be-only indirect (particulars are not facts).

Let us then give a few examples of this sort:

- The green tie my dad used on his way to work. (greeml)

- The pastel colors I used to paint the woods. (greem2)

- The new line of ties that arrived at the store. (greem3)

- The green seen in the neon light. (greem4)

The warning is to not immediately treat these examples as cases of particular green-things or particular green-contents, because we should try to think in terms of "green situations". A comparison with Strawson's "feature-placing" language described in the second part of Individuals (1959) may perhaps be useful in this regard, to the effect that the subject of the examples is the overall quality situation: the quale and not the color. The color here is indissolubly linked to the peculiarity 
of each experienced situation. ${ }^{15}$ In a language of this sort, obviously, there is no sentence divide into subject and predicate and, indeed, according to Strawson there are not even resources for distinguishing, enumerating, and reidentifying particulars of some sort (Hacking, 1968, p. 171). Feature-placing sentences are exclusively aimed at the universal quality of the mentioned feature (which is why it is too complicated a language for our ordinary purposes), but this is where the comparison with Sellars proves particularly useful. The above-described examples (greem 1, greem 2, etc.) fit perfectly with the description of the feature-placing language since they aim to trespass the subject-predicate divide, as well as the substratum theories. In contrast to Strawson, nonetheless, Sellars believes that the fundamental aspect of such a language is to help us imagine qualities that are somewhat unique (Sellars, 1952, p. 187). The idea here is to work the other way around. That is to say: it is not so much a question of imagining "a language without particulars", but rather of making the qualitative dimension of each episode so specific that it should be thought of as falling below the threshold of repetition and re-identification (remember that the key point of Sellars's stipulation is that each basic episode exemplifies one and only one quale). For Sellars also, as it was for Strawson, such a language has only a fictional value and is not meant to replace ordinary language, but while Strawson claims that such fiction is useful, for it makes us aware of the non-dispensability of ordinary language, Sellars holds instead that it is useful in making us aware of the logical requirements implied by our ordinary discourses about particulars.

But what is the connection between the above-mentioned possible greem-episodes? Do they look alike? Strictly speaking, no, because they are different from each other since each exemplifies one and only one qualitative determination (forming only one "ideal object", as Borges previously told us). But why then do we say that they are all greem?

If we responded by identifying a common quality, we would find ourselves in the starting box and it would never end, because once again we would face a dialectical relationship between a universal and a particular. And the same applies if we were to treat such greem-episodes as if they were "facts" containing green-contents. In our case, on the contrary, we are instead in the context of a family resemblance that can never be exhausted once and for all. Some situations are associated by context of use, others involve other "batteries of simple universals" (Sellars, 1952, p. 195). There are possible uniformities, internal relations between different contexts, and such sort of mobile normativity allows us, on the epistemic side to apply material rules of inference (Sellars, 1952, pp. 196-197).

In other words, there are elements, not rigidly defined, but with an open texture, that allow us to think that each particular situation is not a completely closed box, but that it expresses by itself, in a way that is not predictable a priori, affinities with other possible qualitative situations.

\footnotetext{
15 Here we should say a few words about the concept of simplicity: qualia are simple because they instantiate one and the same qualitative determination - the one saturated by the episode in question. But they are not simple in the sense of elementary: the qualia-situations can indeed be very articulated. In this case what can deceive is to treat the quale as if it were sic et simpliciter an atomic fact.
} 
This is what is expressed by the concept of "family of worlds" (Sellars, 1952, p. 196), which denotes a normative context governed by open-textured ties. It is only in this sense that the green, understood as a complex particular, can be identified with a class of particular episodes connected by contexts of use and with open normative ties. Such a normative dimension is the fundamental element of the whole affair and its logical dimension must therefore be borne in mind when we speak of greens in our ordinary language. Because the point is finally this: does our noninferential use of green in the ordinary language really coincide with a form of direct sense content (Sellars, 1963, p. 129)? The arguments developed in LCP, P, and SRLG, aim precisely at putting pressure on the "myth" of direct reference, i.e., they warn against the idea of an immediate givenness, be it epistemic (sense-data) or categorial (constituent ontology).

\section{Particulars are not data, data are not particulars}

To go back to the initial questions, it would be wrong to imagine that Sellars would reason in a foundationalist way (this is a point of difference, as we are going to see in a moment, with the theory of tropes, at least in its classical formulation): his argument is not that there are basic particulars from which universal qualities are formed. Just as it would be another sort of mistake to think that quality is the primitive factor that allows us to define its particular instances. We are not dealing with a top-down, nor with a bottom-up logic. It is more that our ability to speak correctly of greens implies, as its logical counterpart, the recognition of particular green situations. The argument is more pragmatic-linguistic than ontological.

Besides, basic particulars do not have a direct cognitive value (green-situations are not "data" that can be expressed with the resources of ordinary language), but represent, so to speak, the boundary conditions that regulate the meaning of words and that govern the material rules of inference that we use in our ordinary speeches. ${ }^{16}$ Our talk about complex particulars, on their side, do not have a direct link with the "data" they intend to express, but they rather summarize normative ties that connect different situations of usage. Talking about "blue" (epistemic level) implies a complex of particular situations that makes it possible for us to learn pattern governed behaviors, namely, to spend the word correctly in the great variety of possible standard and non-standard situations.

While in the sense-data model there is a starting content that is blue, which we learn directly because its being blue is transmitted to and coincides with our knowledge of it (it is a directly epistemic datum: a particular that counts as a fact, or a fact that is itself a particular), in the complex particulars model "blue" is rather a linguistic or "material position" (Sellars, 1954, p. 331). The particular predicate expresses but a linguistic positioning. It implies blue or green-situations, but it is

\footnotetext{
16 Sellars describes LCP as "a study in the foundations of logic", which is indeed "a study of the characteristic features which must be present in a language about a world of fact” (Sellars, 1949, p. 314).
} 
not defined by its descriptive content: it is not a mirroring-word, but rather embodies a pattern-governed behavior. The utterance "green" is responsive to a way of functioning. ${ }^{17}$ Needless to say, if we say "green!" it will be highly plausible to find some stimulating patterns somewhere around us, but it would be wrong to think of such a response as an inferential move having the stimulus as its immediate premise (Sellars, 1954, pp. 328-329). The response is not a representational-pattern mirroring the stimulus; and inferences, as such, are only and exclusively norm-governed intra-linguistic moves. Material positions are, in conclusion, primitive sentences whose peculiar qualification (i.e., the fact of containing "particular predicates" as well as an intrinsic lawfulness) makes them able to perform a "catalytic function" (Sellars, 1954, p. 330) within our ordinary linguistic games, insofar as they provide the possibility of making (material) inferential transitions.

In conclusion, if we talk about empirical knowledge, even in non-inferential cases, it is always facts about particulars that are known, but never particulars in their immediacy.

\section{Tropes variations}

So far I have never mentioned tropes. But the temptation to assimilate basic particulars to the theory that Donald Cary Williams exposed in 1953 is very strong. It is therefore time to make some remarks on the subject.

First of all, some diachronic reference: Sellars's essays (LCP, P, SRLG, EPM) date 1949, 1952, 1954 and 1956 respectively; while Williams's On the Elements of Being dates to 1953. But despite the chronological contiguity neither does Sellars refer to Williams's works nor does the latter refer to the work of the former. There would be some interesting material for historical research (Fisher, 2017), but here I would like to develop another set of considerations. First, the similarity between the two theories:

- both abstract particulars (tropes) and complex particulars are designed to create an alternative to bare particularism and bundle theories;

- in both cases new entities, i.e. "particularized universals", are introduced;

- tropes, as well as basic particulars, are mutually distinct "no matter how closely two of them may resemble one another" (Campbell, 1990, p. 53);

- in both cases the relationships among particulars are explained with the help of a resemblance-theory which is not further analyzable (albeit on different grounds);

- to some extent, naturalism represents the background of both theories (even if they profess distinct forms of naturalism, which are very peculiar and not mutually overlapping). ${ }^{18}$

\footnotetext{
17 There is an important passage in SRLG connecting the analysis developed on particulars with the new interpretation of the language proposed by Sellars: "it is by virtue of its material moves (or, which comes to the same thing, its material auxiliary positions) that a language embodies a consciousness of the lawfulness of things" (Sellars, 1954, p. 331).

${ }^{18}$ For more references on the "metaphysical naturalism" proposed by Williams, see Williams (1944) and Fisher (2017).
} 
The similarity continues also from a performative point of view, in the sense that both theories, on the basis of their respective premises, manage to solve the problems for which they were designed: Williams, for example, explains that an advantage of his position is that all universal abstracts are easily explained, because they are composed of tropes (Williams, 1953a, 1953b, p. 8). Not only that, but the acceptance of tropes also solves the long-standing problem of the relationship between property and individuals. From the point of view of theory, in fact, if we affirm that "Socrates is wise" there is no longer a subject and a predicate that in some way must be linked together, but a simpler story leaks out: Socrates is a sum of tropes and among the tropes that make him up there is also that of wisdom. This trope is also a member, by resemblance, of the class of tropes that constitute "Wisdom" as an abstract universal (Williams, 1953a, 1953b, p. 11). And so also the problem of the indiscernibles finds a solution: different entities can share the same properties and, however, keep their difference not because of some identifying bare-factor, but simply because there are no identical tropes (Campbell, 1990, p. 44). There are, therefore, similarities and they have also been recognized to some extent (Campbell, 1990, p. xii).

There are nonetheless differences, which in some ways are even more interesting to analyze than analogies. The first one concerns the fact that from Williams onwards tropes have mainly been understood as part of a "constituent ontology" (Loux, 2015). For how they are constructed, tropes express a one-category ontology: they represent "the very alphabet of being" (Williams, 1953a, 1953b, p. 7), insofar as they are part of a theory that is "first and foremost a theory of the ontic constitution of the cosmos". Our world is therefore a world of tropes (Campbell, 1990, p. 24). But the same cannot be said of Sellars. The latter is a convinced nominalist, but he does not espouse a particularist ontology. In the essays we have previously encountered (LCP, P, SRLG), the emphasis was not so much on ontology, but rather on the logical requirements implied by our discourses about particulars. Needless to say, given his standing commitment to naturalistic nominalism, he is also committed to the kinds of things we can explicitly name in the empirical statements we take to be true (deVries, 2021). Indeed, the point of greatest interest as well as of greatest divergence is the following: what kind of entity are the "complex particulars" described by Sellars? Is it just a coincidence that in $\mathrm{P}$ he mentions only three times the word "ontology", putting it in quotation marks in all three cases (Sellars, 1952, pp. 192, 197 and 198)? Somewhere in the text we find an important footnote in which he says that his "substantive contentions" are more pertinent to logic than to the "epistemology of logic" and that if the overall frame of his paper may sound "ontological", this is admittedly a misleading appearance for the sake of simplicity in his exposition (Sellars, 1952, p. 192).

There are two distinctive features of Sellars's quasi-tropes theory: the linguistic approach (SRLG, EPM) and the pragmatic strategy (P, SRLG, EPM). In both cases it is an anti-metaphysical move that defines the peculiarity of his nominalist and naturalistic proposal. It is for this reason that his project does not supposedly belong to a constitutive ontology. But it is precisely for this reason-for having sustained a quasi-tropist model on the basis of independent reasons - that the most theoretically stimulating comparison is not so much the one he entertained 
with Williams, but the one linking his trope-variations to the positions of some contemporary tropists (it is well known, in fact, that in the archipelago of tropetheories very different positions emerge-Maurin, 2018, p. 1; Garcia, 2015, p. 134).

Such is the case, for example, of Jonathan Lowe, who justifies the existence of tropes with arguments very similar to those proposed by Sellars. First of all, he says, we should not decide between regarding properties as universals and regarding them as particulars, because "we ought to include both categories of entity as fundamental ones in our ontology" (Lowe, 2008, p. 175). This is a truly remarkable point, because so far we have talked about basic particulars, assimilating them to tropes, but let us always keep in mind that the key concept for Sellars is that of complex particular, which serves precisely to implement the inclusive strategy proposed by Lowe. Sellars's particulars perform both a universalizing as well as an identifying function and it is precisely the accomplishment of this double function that makes his proposal so appealing: particulars are not made up of a bundle of universals, but not even universals are made up of particular-tropes. We would fall to the latter case if Sellars accepted an ontological conception of tropes (assimilating his position to that of Williams), but it is precisely this ontological reduction that he explicitly denies.

His basic particulars, besides a logical-linguistic characterization (LCP, P, SRLG), possess a pronounced phenomenological nuance (especially present in EPM) and this is the side that connects his theory to the topic of "visible property" developed by Lowe (Lowe, 2008, p. 187). According to the latter, the key point to establish what is properly visible in a particular instance of green is to hold on to the distinction between "epistemic" and "non-epistemic" seeing. Lowe argues:

Very arguably, one can see a green leaf, and even see its greenness, without seeing that the leaf is green. The point concerns a distinction made by Fred Dretske between "epistemic" and "non-epistemic seeing" (Lowe, 2008, p. 189).

Lowe claims he refers to Seeing and Knowing by Dretske (1969), but a reference to Sellars would be more appropriate, because it is Sellars who first and properly distinguished between "seeing of" and "seeing as" (O'Shea, 2007, pp. 34-36). The distinction between the pure descriptive content of a phenomenological experience and its conceptual classification is an integral part of Sellars's attempt to disambiguate the relationship between "facts" and "particulars", and it is one of the theoretical main assets of both P and EPM. It is quite significant in fact that Lowe states that he wants to go beyond Dretske on the basis of the following reasons:

I am inclined, in any case, to go even further than Dretske and say that 'seeing that' is not really a kind of seeing at all. What we standardly report using the "seeing that" construction is, I suggest, not literally an episode of virtual perception as such, but rather a perceptual judgement or belief - such a judgement or belief being one that a percipient makes or forms on the basis of an episode of visual perception, but which should not be confused with that episode itself (Lowe, 2008, p. 189). 
The previous analysis allows us to grasp his proposal on the fly: one thing is the seeing of a particular, another thing is the assertion of a fact about a particular (a "seeing that" report); and still another thing is to treat the epistemic fact as if it were a particular itself. Here is the root of the distinction between "seeing of" and "seeing that": one should carefully distinguish between the phenomenological experience of a greem (rich in content, but literally unspeakable), from the utterance of an observational report, which requires concepts to be mobilized and to be arranged in a propositional or quasi-propositional form. The perceptual judgment, as Lowe correctly remarks, "should not be confused with that episode itself". And that's for a pretty simple reason:

"S sees that the leaf is green" does not, in itself, tell us what entities $S$ sees, only what $\mathrm{S}$ judges or believes on the basis of his or her visual experience (Lowe, 2008, p. 190). ${ }^{19}$

The perceptual report produced by a subject makes us aware of the fact that the subject is referring to a descriptive content, but it does not give a name to this content and this is the problem of particulars and of the confusion that arises when we treat epistemic facts as if they were particulars themselves. It is one thing to say that the "athlete who won the $100 \mathrm{~m}$ at the Beijing Olympics is the same athlete who won the $100 \mathrm{~m}$ at the London Olympics", it is another thing to say that it is Usain Bolt who has accomplished this extraordinary feat (I take the example in a modified form from deVries-Triplett, 2000, p. 161).

The problem involved by particulars is also and foremost a linguistic problem ("we want to have a name for this kind of experience which is truly a name, and not just shorthand for a definite description"-Sellars, 1963, p. 154): it is a phenomenological problem that fully affects the functioning of ordinary language.

This consideration leads us to another tropes variation, this time crossing the arguments developed by Friederike Moltmann (2004, 2013). With regard to the ontology we accept once we use a natural language, Moltmann in fact argues that the acceptance of tropes allows us to question the so-called "Fregean criterion of objecthood" that links together the syntax of the language to ontology (Moltmann, 2004 , p. 38). The idea is more or less like this: according to the Fregean view, singular terms usually stand for objects or for property objects; that means that the terms we actually employ in our natural language basically refer to particulars (objects) or properties (metaphysical objects or universals). Such a scheme should always apply, because it is only the compliance with this criterion that allows for the production of meanings. So in cases of "bare nominalizations", like for instance "wisdom", we

\footnotetext{
19 To be more accurate, we should observe that, from a Sellarsian point of view, it is not correct to say that the perceptual report doesn't tell us what entities S sees, for if we deal with veridical reports, they can be true only if $a$ is F-and this commits us to what entities she actually sees. But as I will try to explain below, the point raised by Lowe concerns the specific nameability of what is seen (because, strictly speaking, we should add that S does not see a "green leaf", but "a particular kind of leaf seen in a specific lighting context, endowed with a particular chromatic content" and so on). It is in this specific problem of naming that I seem to identify a point of convergence between the tropist variations, such as Lowe's one, and the viewpoint expressed by Sellars.
} 
face terms that stand for entities that should be considered universals (Moltmann, 2004 , p. 4). Somehow the universal is transformed into an "object" in a metaphysical sense and that is why it is able to display properties of its own.

Moltmann's idea is precisely to put this nominalization criterion under pressure. She thinks that singular terms apparently referring to universal properties (metaphysical objects) actually refer to "entities that act as non-objects, namely universals of the sort that I called 'kinds"” (Moltmann, 2004, p. 38). The heart of her proposal is therefore the following:

A singular term may just stand for an entity that plays a role for semantic predicate-argument relations, but is not itself a bearer of properties and thus not an object. Its function may just be that of helping make statements about particulars. (Moltmann, 2004, p. 39)

The key concept here is "to play a role": the singular term stands neither for a particular nor for a particulizer, but performs a semantic function and this semantic function is all that reference is. The reference, says Moltmann, is to a universal whose instances are "concrete property manifestations, but which does not have the status of an object". This type of object is called "kind of tropes" (Moltmann, 2004, pp. 1-2). The discourse is therefore entirely performative, since it is specified that:

Kinds are entities that play the same semantic roles as objects in that they can act as semantic values of singular terms and as arguments of predicates (Moltmann, 2004, p. 23)

Once again, the key word is "semantic role": tropes are not part of a constituent ontology, but rather they play a functional role in supporting us in making correct statements in our ordinary discourses. Namely, tropes are particularized universals, even though they are not metaphysical objects. Moltmann does not say this expressly, but the semantic value of her kinds of tropes seems to be linked to a value of use, since the introduction of these "entities that act as non-objects" seems to explain the ability of the speaker to perform proper material inferences.

I am not sure Moltmann would accept this interpretation that emphasizes the Sellarsian side of her theory (which has extended to embrace the semantics of bare demonstratives like this and that-Moltmann, 2013, p. 346), yet the integration degree between the two models is surprising. Especially with regard to the use that they both make of the notion of particularized universal. Let us remember that for Sellars the complex-particular "green" does not refer so much to an object or to a green-content, but names a functional link subsisting between green-situations. There is perhaps a more markedly pragmatic aspect in Sellars, in the sense that the word "green" expresses a certain type of functioning, since predicates functionally classify usage bonds and do not denote objects. But both in Sellars and in Moltmann the semantic scheme seems to follow similar tracks. And it is remarkable that for the two of them the recourse to tropes constitutes a sort of logical implication related to the functioning of ordinary language and not a primitive ontological assumption.

After all, in Sellars too the project of conceptual-role semantics is absolutely supportive of the logical analysis underlying the particulars, to the point that the 
former can be considered as a filiation of the latter. The fresh interpretation of the language announced in P and later developed in SRLG constitutes, in fact, a unique theoretical block that will also be maintained in EPM, and it constitutes the theoretical backbone of his so-called "psychological nominalism" (Sellars, 1963 , p. 160). What is striking, at the end of the analysis, is that both Sellars and Moltmann have an exquisitely linguistic approach to tropes and this seems to me a remarkable point of commonality, even if their positions probably differ regarding the adoption of conceptual-role semantics. But the fact remains that by virtue of tropes, they both manage to de-metaphysicalize the status of universals while at the same time preserving their role and their function.

\section{Conclusions}

It is hard to tell if Sellars actually supported a tropes theory. But surely for a certain period of time he developed a theory of particulars. And the latter played a decisive role in the constitution of some of the most characteristic features of his philosophy. It is surprising to note how this topic, with some notable exceptions, has remained under-determined in the field of Sellarsian studies, just as it is surprising that it has never appeared in the literature on tropes. But there have not even been studies on Sellars and Williams, despite the almost temporal overlapping of their theories.

Certainly, Sellars's views on particulars has a still unexpressed theoretical potential. And the attempt of this paper was in fact twofold: (1) to bring to light the features of his theory; (2) to show its high degree of compatibility with some theses supported by contemporary tropists. Is it possible to import the "complex particulars" model into the contemporary debate? And is it possible to do so extrapolating it from the complex systematic architecture of Sellars's thought? At the moment, we have no answers in this sense. But one direction of investigation has been-I hopesketched out.

Funding Open access funding provided by Università degli Studi di Padova within the CRUI-CARE Agreement.

Open Access This article is licensed under a Creative Commons Attribution 4.0 International License, which permits use, sharing, adaptation, distribution and reproduction in any medium or format, as long as you give appropriate credit to the original author(s) and the source, provide a link to the Creative Commons licence, and indicate if changes were made. The images or other third party material in this article are included in the article's Creative Commons licence, unless indicated otherwise in a credit line to the material. If material is not included in the article's Creative Commons licence and your intended use is not permitted by statutory regulation or exceeds the permitted use, you will need to obtain permission directly from the copyright holder. To view a copy of this licence, visit http://creativecommons.org/licen ses/by/4.0/. 


\section{References}

Bailey, A. M. (2012). No bare particulars. Philosophical Studies, 158, 31-41.

Bergmann, G. (1947). Russell on particulars. The Philosophical Review, 56(1), 59-72.

Borges, J. L. (1964). Tlön, Uqbar, Orbis Tertius. In A. Yates \& J. E. Irby (Eds.), Labyrinths. New York: Selected Stories \& Other Writings. New Direction Publishing.

Broad, C. D. (1933). Examination of McTaggart's Philosophy. London: Cambridge University Press.

Campbell, K. (1990). Abstract Particulars. Basil Blackwell.

Connolly, N. (2015). Yes: Bare Particulars! Philosophical Studies, 172, 1355-1370.

deVries, W., \& Triplett, T. (2000). Knowledge Mind and the Given. Reading Sellars's Empiricism and the Philosophy of Mind: Hackett Publishing Company, Indianapolis.

deVries W. (2021 Summer Edition). Wilfrid Sellars, The Stanford Encyclopedia of Philosophy, Edward N. Zalta (ed.). Retrieved July 13 2021, from https://plato.stanford.edu/archives/spr2021/entries/sella rs.

Di Bella, S. (2005). The Science of the Individual: Leibniz's Ontology of Individual Substance. Springer.

Dretske, F. (1969). Seeing and Knowing. University of Chicago Press.

Fisher, A. R. J. (2017). Donald C Williams's defence of real metaphysics. British Journal for the History of Philosophy, 25(2), 332-355.

Garcia, R. (2014). Bare particulars and constituent ontology. Acta Analytica, 29, 149-159.

Garcia, R. K. (2015). Is trope theory a divided house? In G. Galluzzo \& M. J. Loux (Eds.), The Problem of Universals in Contemporary Philosophy (pp. 133-155). Cambridge University Press.

Hacking, I. (1968). A language without particulars. Mind, 77(306), 168-185.

Jones, J. R. (1950). Simple particulars. Philosophical Studies, 1(5), 65-74.

Leibniz, G. W. (A) Sämtliche Schriften und Briefe. Edited by the Deutsche Akademie der Wissenschaften zu Berlin. Darmstadt, 1923 ff., Leipzig, 1938 ff., Berlin, 1950 ff. Cited by Series (Reihe) and Volume (Band).

Leibniz, G. W. (1963). (GM) Leibnizens mathematische Schriften. 7 vols. In C. I. Gerhardt (Ed.), Weidmann, Halle (pp. 1849-1863). Reprint, Georg Olms: Hildesheim 1961-62.

Leibniz, G. W. (GP) Die philosophischen Schriften von Gottfried Wilhelm Leibniz, 7 vols. In C. I. Gerhardt, W. Halle (Eds.), (pp. 1875-1890). Reprint, Georg Olms: Hildesheim 1960-61

Loux, M. J. (2015). An exercise in constituent ontology? In G. Galluzzo \& M. J. Loux (Eds.), The Problem of Universals in Contemporary Philosophy (pp. 9-45). Cambridge University Press.

Lowe, E. J. (2008). Tropes and perception. In S. Gozzano \& F. Orilia (Eds.), Tropes (pp. 175-192). Universals and the Philosophy of Mind, Ontos Verlag.

MacBride, F. (2018). On the Genealogy of Universals: The Metaphysical Origins of Analytic Philosophy. Oxford University Press.

Maclean, G. K. (2014). Bertrand Russell's Bundle Theory of Particulars. Bloomsbury Academic.

Maurin, A.S. (2018 Summer Edition). Tropes, The Stanford Encyclopedia of Philosophy, Edward N. Zalta (ed.). Retrieved July 13 2021, from https://plato.stanford.edu/archives/sum2018/entries/tropes.

Moltmann, F. (2004). Properties and kind of tropes: new linguistic facts and old philosophical insights. Mind, 113(449), 1-41.

Moltmann, F. (2013). Tropes, bare demonstratives, and apparent statements of identity. Nô̂s, 47(2), $346-370$.

Morganti, M. (2012). Sellarsian particulars. Acta Analytica, 27(3), 293-306.

Nunziante, A. M. (2018). The lingua franca of nominalism. Sellars on Leibniz. In L. Corti \& A. M. Nunziante (Eds.), Sellars and the History of Modern Philosophy. New York and London: Routledge.

O'Shea, J. R. (2007). Wilfrid Sellars. Polity, Cambridge: Naturalism with a Normative Turn.

Olen, P. (2016). Wilfrid Sellars and the Foundations of Normativity. Palgrave MacMillan.

Rauzy, J. B. (2009). Sellars et Bergmann Lecteurs de Leibniz. La querelle des particuliers. In M. Monnoyer \& B. Langlet (Eds.), Gustav Bergmann Phenomenological Realism and Dialectical Ontology (pp. 87-102). Frankfurt a.M: Ontos Verlag.

Russell, B. (1940). An Inquiry into Meaning and Truth. Georg Allen and Unwin.

Sellars, W. (1949). On the logic of complex particulars. Mind, 58, 306-338.

Sellars, W. (1952). Particulars. Philosophy and Phenomenological Research, 13, 184-199.

Sellars, W. (1953). Inference and meaning. Mind, 62, 313-338.

Sellars, W. (1954). Some reflections on language games. In W. Sellars (Ed.), Science, Perception and Reality (pp. 321-358). Routledge and Kegan Paul. 
Sellars, W. (1959). Meditations leibnitziennes. In W. Sellars (Ed.), Philosophical Perspectives (pp. 153181). Charles Thomas Publisher.

Sellars, W. (1963). Empiricism and the philosophy of mind. In W. Sellars (Ed.), Science, Perception and Reality (pp. 127-196). Routledge and Kegan Paul.

Sider, Th. (2006). Bare particulars. Philosophical Perspectives, 20, 387-397.

Simons, P. (1994). Particulars in particular clothing: Three trope theories of substance. Philosophy and Phenomenological Research, 54(3), 553-575.

Stout, G. F. (1930). Studies in Philosophy and Psychology. London: MacMillan and Co.

Strawson, P. F. (1959). Individuals. Routledge, London and New York: An Essay in Descriptive Metaphysics.

Williams, D. C. (1944). Naturalism and the nature of things. The Philosophical Review, 53(5), 417-443.

Williams, D. C. (1953a). On the elements of being I. Review of Metaphysics, 7, 3-18.

Williams, D. C. (1953b). On the elements of being II. Review of Metaphysics, 7, 171-192.

Publisher's Note Springer Nature remains neutral with regard to jurisdictional claims in published maps and institutional affiliations. 